\title{
BMJ Open A systematic review of interventions to support the careers of women in academic medicine and other disciplines
}

\author{
Kate E Laver, ${ }^{1}$ Ivanka J Prichard, ${ }^{2}$ Monica Cations, ${ }^{1}$ Ivana Osenk, ${ }^{2}$ Kay Govin, ${ }^{2}$ \\ John D Coveney ${ }^{2}$
}

To cite: Laver KE, Prichard IJ, Cations M, et al. A systematic review of interventions to support the careers of women in academic medicine and other disciplines. BMJ Open 2018;8:e20380. doi:10.1136/ bmjopen-2017-020380

- Prepublication history and additional material for this paper are available online. To view these files, please visit the journal online (http://dx.doi. org/10.1136/bmjopen-2017020380).

Received 1 November 2017 Revised 8 January 2018 Accepted 6 February 2018

Check for updates

${ }^{1}$ Department of Rehabilitation, Aged and Extended Care, Flinders University, Adelaide, Australia

${ }^{2}$ College of Nursing and Health Sciences, Flinders University, Adelaide, Australia

Correspondence to

Dr Kate E Laver;

Kate.Laver@sa.gov.au

\section{ABSTRACT}

Objective To summarise quantitative evaluations of interventions designed to support the careers of women in academia of any discipline.

Method A systematic search of English entries in PubMed, CINAHL and Google Scholar was conducted in September 2017. Methodological quality of the studies was independently assessed by two authors using the Joanna Briggs Institute quality appraisal checklists. Metaanalysis was not possible due to heterogeneity in methods and outcomes; results were synthesised and displayed narratively.

Results Eighteen eligible studies were identified, mostly evaluating programmes in academic medicine departments. The most common interventions were mentoring, education, professional development and/or networking programmes. All programmes took a 'bottomup' approach in that women were responsible for opting into and devoting time to participation. Study quality was low overall, but all studies reported positive outcomes on at least one indicator. Most often this included improvements in self-rated skills and capabilities, or satisfaction with the programme offered. Results regarding tangible outcomes were mixed; while some studies noted improvements in promotion, retention and remuneration, others did not.

Conclusions This review suggests that targeted programmes have the potential to improve some outcomes for women in academia. However, the studies provide limited high-quality evidence to provide information for academic institutions in terms of the best way to improve outcomes for women in academia. The success of an intervention appears to be undermined when it relies on the additional labour of those it is intending to support (ie, 'bottom-up' approaches). As such, academic institutions should consider and evaluate the efficacy of 'top-down' interventions that start with change in practice of higher management.

\section{INTRODUCTION}

There is increasing focus on gender inequality in academia and the under-representation of women in senior academic positions internationally. ${ }^{12}$ While a trend towards parity among all academic staff has been noted in many countries, ${ }^{3-5}$ figures decline sharply with seniority. In the UK, only

\section{Strengths and limitations of this study}

This review builds on extensive literature regarding the contributors to gender inequality in academic medicine and other disciplines, and synthesises current evidence regarding interventions to address this inequality.

- Included studies are limited to those reporting quantitative outcomes only, with a focus on tangible outcomes such as retention, promotion, research grant success and salary.

- Meta-analysis was not possible due to heterogeneity in methods and descriptive presentation of results.

- Methodological quality of the studies was low overall, making it difficult to determine the program elements most important for success.

$18 \%$ of Professors of Medicine are women, ${ }^{6}$ and in Australia women represent less than one-third of academic staff above the senior level (Senior Lecturer). ${ }^{3}$ Similar imbalances are reported in Germany, the USA and, to a smaller extent, Nordic countries. ${ }^{7-10}$ Women of colour are particularly affected, accounting for only $7.5 \%$ of all full-time faculty in the $\mathrm{USA}^{11}$ and $0.9 \%$ of Professors in the UK. ${ }^{5}$ Progress on addressing this problem is slow. The proportion of female full Professors in Medicine in the USA has only grown by $7 \%$ (to $17 \%$ total) in the last three decades. 41213 Women remain under-represented on editorial boards, have fewer publications in highranking medical journals, are less likely to be awarded research funding and receive less funding in relative terms. ${ }^{14} 15$ They are also more likely to leave academia. ${ }^{16}$

Suggested reasons for this under-representation include formal and informal gendered hiring practices that begin at the point of recruitment. ${ }^{17}$ For example, fewer women are involved in the selection process of new staff, $^{17}$ and women are less likely to benefit from networks with more senior (and usually male) faculty, a key barrier to promotion. ${ }^{17}$ Women are considered less capable and 
suited for leadership than their male counterparts, ${ }^{18} 19$ and when exhibiting traits that are considered signs of leadership when demonstrated in men (eg, assertiveness, competitiveness), women can attract penalisation or loss of credibility. ${ }^{20}$ Women also more often engage in equalising behaviour that is not valued or tied to career advancement. ${ }^{12}$ Women with children are disadvantaged in a variety of ways particularly if they take time away from work to care for their children. This includes reduced research publication outputs and chances of being recruited, lower perceived credibility and difficulties with 'catching up' to their male counterparts on return to work. ${ }^{81-23}$ While women are usually aware of these inequalities, they report sensing a complacency among upper management and fear being considered a 'trouble maker' if they take assertive action (and the damage to career that can result). ${ }^{24}$

Given the complexity and wider causes of gender inequality in academia, interventions to improve conditions are likely to be similarly complex. Identification and implementation of evidence-based intervention programmes that improve parity are essential considering the rights of women to equal opportunity and the noted benefits of staff diversity. ${ }^{25}$ The under-representation of women in senior academic positions is a waste of public investment in women's capital, deprives research of women's perspectives and stunts the economic growth of the sector as a whole. ${ }^{2627}$ Several approaches to addressing the problem have been trialled, but whether these contribute to quantifiable benefits for women (such as promotion or remuneration) is not well understood.

The aim of this systematic review is to identify intervention programmes intended to support the careers of women in academia, to describe and synthesise the quantifiable outcomes of these programmes and to identify the most efficacious programme elements. This information can then be used to guide academic institutions in programme design and delivery.

\section{METHOD}

We drafted a protocol for this review 'a priori' and inclusion criteria were developed prior to commencing the search. We report according to the Preferred Reporting Items for Systematic Reviews and Meta-Analyses (PRISMA) guidelines, and a checklist of PRISMA items is presented in the online supplementary data S1.

\section{Eligibility criteria}

Studies were eligible for inclusion in the review if

- The population of interest was women in any field in academia;

- The study evaluated an intervention specifically intended to improve outcomes for these women;

- Some form of quantitative evaluation was conducted; and
- Outcomes included self-rated attitudes/efficacy or concrete measures of success (eg, funding, promotion, publications).

Studies were excluded when

- The intervention population was not specific to women, for example, where institutions looked to increase ethnic, gender and socioeconomic diversity in tandem. Studies that assessed existing opportunities for career development, rather than evaluating a specific programme, were also excluded;

- The study did not conduct a formal evaluation of a programme or used qualitative or narrative outcomes, which were beyond the scope of this review. Included studies were limited to quantitative studies to identify quantifiable outcomes on objective measures; and

- Only a conference abstract was available with insufficient detail about study methods or results.

\section{Data sources and searches}

We searched PubMed (1966 onwards) and CINAHL (1981 onwards) for English-language studies published any time to September 2017. The search strategy (available in online supplementary data S2) was deliberately broad in an effort to gather all eligible studies. Reference lists of all included studies were hand-searched for additional records. We also searched grey literature via Google and Google Scholar.

\section{Study selection and data extraction}

Two authors (KEL and MC) reviewed titles, abstracts and full-text papers for eligibility. Authors resolved disagreement by discussion or, where necessary, a third author (IP) offered their view. Another author (IO) was responsible for extracting data using a standardised data sheet that was piloted with three papers and revised. All data extraction was verified by MC, and disagreement was resolved via discussion. Extracted data included study design, participants, intervention details, comparators, outcome assessed and method, and relevant statistical data.

\section{Quality assessment}

Two people (KEL and MC) independently assessed the methodological quality of each study using the Joanna Briggs Institute (JBI) battery of quality appraisal tools. ${ }^{28}$ This battery was chosen because it offers a range of checklists suitable for a variety of study designs, which is useful given the breadth of study types included here. The tools also rank well in systematic evaluations of quality assessment tools. ${ }^{29}$ An amended version of the eight-item Checklist for Analytical Cross-Sectional Studies was used for observational and post-test only design studies, removing item four ('Were objective, standard criteria used for measurement of the condition?') because the 'condition' was central to every study. Pre-test and post-test studies or controlled studies were appraised using the nine-item JBI Checklist for Quasi-Experimental Studies. Both checklists include 


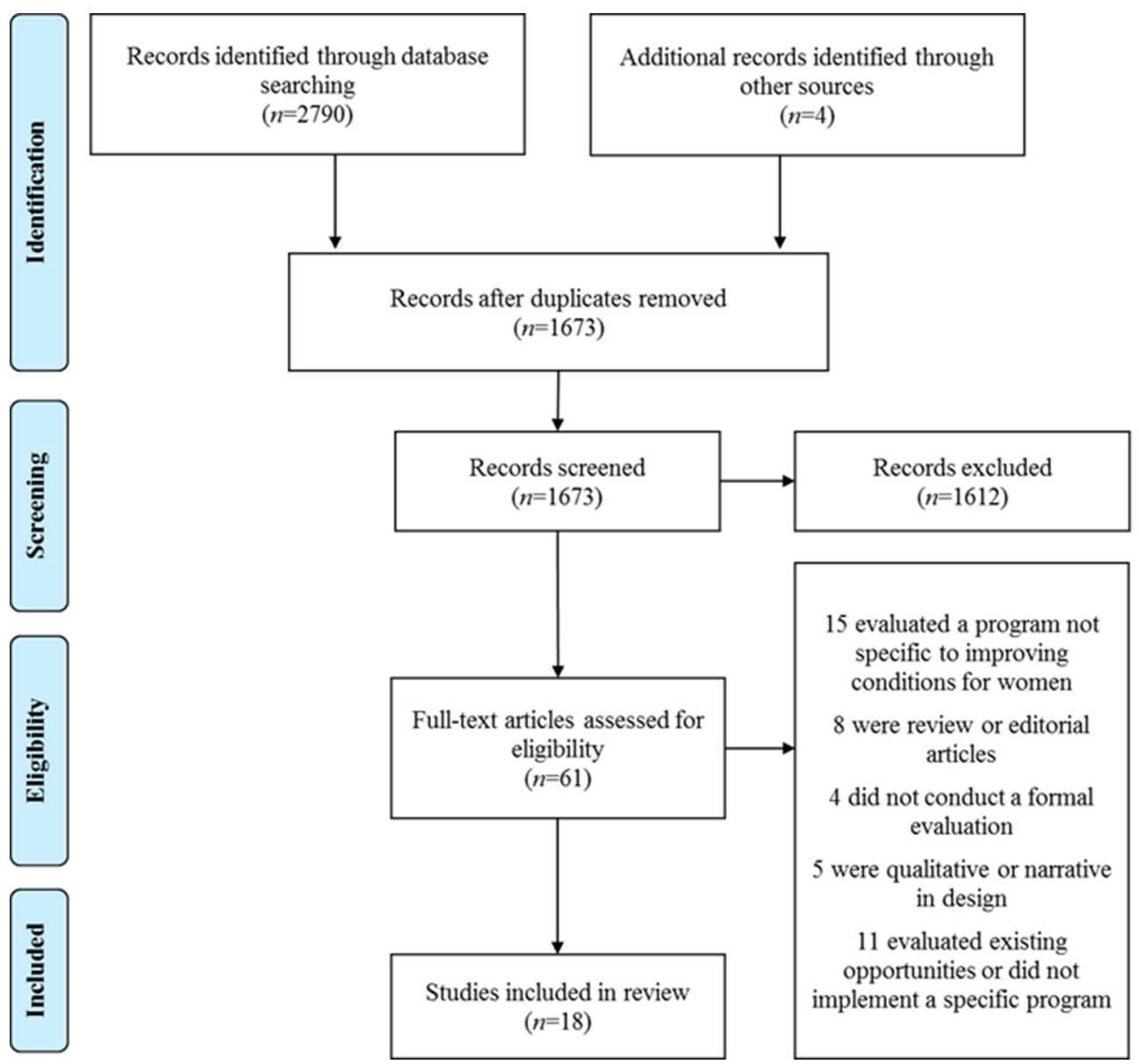

Figure 1 Preferred Reporting Items for Systematic Reviews and Meta-Analyses flowchart describing the process of study selection.

yes/no questions assessing study reproducibility (maximum score 7 and 9, respectively).

\section{Data synthesis}

Due to significant heterogeneity regarding interventions, comparison groups, outcomes of interest, outcome measurement and statistical analysis, it was not possible to conduct meta-analysis.

\section{RESULTS}

The search of the electronic databases revealed 2790 citations (figure 1). A search of reference lists and the grey literature revealed four further relevant studies. Of the citations identified, 61 full-text articles were reviewed and 18 were found to meet all inclusion criteria (see table 1 ).

\section{Characteristics and quality of included studies}

Studies were published between 2001 and 2016 and all but two ${ }^{30}{ }^{31}$ took place in the USA. Fifteen were implemented in academic medicine departments, while the other three ${ }^{303233}$ were implemented across multiple departments (including medicine). Most samples were relatively small (with as few as four participants ${ }^{34}$ ) except in one study where several thousands of faculty members over time were included in analyses. ${ }^{35}$ Interventions were provided for senior faculty (Assistant/Associate Professor and above) in four studies, ${ }^{36-38}$ junior faculty in five studies, ${ }^{30} 31343940$ all female faculty in five studies $^{32} 3541-43$ and all faculty (male and female) in four studies. ${ }^{334-46}$ Interventions targeting junior faculty were typically focused on peer mentoring, career development skills and support to return to work after having children, while programmes for senior faculty involved upskilling in administrative leadership and conflict management. Programmes delivered to all faculty (men and women) involved education about the impact of gender bias and techniques to improve equity or, in one case,${ }^{46}$ providing better support to new fathers. None of the studies specified the ethnicity of their sample.

The methodological quality of study designs was low to moderate overall. Only three studies included a comparison group using controlled before and after $^{3036}$ or cohort design. ${ }^{35}$ Members of the comparison group were either matched on level and time at the University ${ }^{30}$ or drawn from those who had applied to be part of the programme but had not been accepted. ${ }^{36}$ Of the 15 studies that did not include a comparison group, four used an observational design with the whole faculty or institution, ${ }^{33} 384346$ four conducted evaluations of programme participants at 
Table 1 Details of interventions assessed in included studies

\begin{tabular}{|c|c|c|c|c|}
\hline Study, country & Country & Programme type & $\begin{array}{l}\text { Length of } \\
\text { programme }\end{array}$ & Details \\
\hline McDade et $\left.a\right|^{37}$ & USA & Multicomponent (ELAM) & 1 year & See above \\
\hline Stewart et $\left.a\right|^{33}$ & USA & Peer education & Not specified & $\begin{array}{l}\text { Creation of a faculty committee of full professors in science and } \\
\text { engineering (three women, four men), trained to understand } \\
\text { contributors and consequences of gender inequality in academia. } \\
\text { Brainstormed methods to improve hiring practices in their department } \\
\text { over } 20 \text { hours of meetings. Dissemination via } 26 \text { workshops with their } \\
\text { department staff (details not specified) }\end{array}$ \\
\hline Seritan et al $^{42}$ & USA & Multicomponent & Ongoing & $\begin{array}{l}\text { Women faculty invited to participate in the Society of Women in } \\
\text { Academic Psychiatry group. Intervention included } \\
\text { Peer mentoring } \\
\text { Online collaboration on scholarly projects } \\
\text { Events with special guests } \\
\text { Liaison with interdisciplinary teams } \\
\text { Professional development regarding research resources, } \\
\text { collaborative writing, leadership and negotiation skills }\end{array}$ \\
\hline Gardiner et $a l^{30}$ & Australia & Peer mentoring & Ongoing & $\begin{array}{l}\text { Women academics at lecturer level with mixed teaching and research } \\
\text { roles invited to be mentored by a senior faculty member. } \\
\text { Education workshops on mentoring provided to both mentors and } \\
\text { mentees } \\
\text { Dyads decided on the frequency, length and content of their meetings } \\
\text { (based on the suggested } 1 \text { hour per month) }\end{array}$ \\
\hline Von Feldt et $a l^{47}$ & USA & CV review & One session & $\begin{array}{l}\text { Women assistant professors invited to submit CV for review by a } \\
\text { mentor of their choice (in a different department). } \\
\text { Mentor provided feedback regarding CV, promotion and resources } \\
\mathrm{CV} \text { reviews occurred at a conference during a break }\end{array}$ \\
\hline Dutta et $\left.a\right|^{31}$ & UK & Peer mentoring & 1 year & $\begin{array}{l}\text { Women academics at senior lecturer level or below invited to be } \\
\text { mentored by a senior faculty member of their choice } \\
\text { Mentors received training in developmental mentoring }\end{array}$ \\
\hline Carnes et $\left.a\right|^{45}$ & USA & Peer education & 2.5 hours & $\begin{array}{l}\text { Delivery of a } 2.5 \text {-hour bias literacy workshop in individual } \\
\text { departments, to improve awareness of gender bias and its } \\
\text { consequences in academia. Four elements: } \\
\text { 1. Generating recognition of a need to change and desire to act } \\
\text { 2. Providing tools to engage in new behaviour } \\
\text { 3. Helping envision a link between action and desired outcome } \\
\text { 4. Facilitate deliberate practice }\end{array}$ \\
\hline
\end{tabular}

Continued 
Table 1 Continued

\begin{tabular}{lllll}
\hline Study, country & Country & Programme type & $\begin{array}{l}\text { Length of } \\
\text { programme }\end{array}$ & Details \\
\hline Varkey et $a l^{40}$ & USA & Peer mentoring & 1 year & $\begin{array}{l}\text { Women faculty at either instructor or assistant professor rank were } \\
\text { invited to join a peer mentoring group with others at similar rank }\end{array}$ \\
& & & $\begin{array}{l}\text { Five groups formed, each with a facilitator experienced and trained in } \\
\text { group development. Group mentoring sessions occurred at least once } \\
\text { monthly }\end{array}$
\end{tabular}
monthly

Bauman et $a^{46} \quad$ USA Multicomponent 1 year

Valantine et $a l^{43} \quad$ USA Multicomponent Ongoing
Women faculty invited to participate in the Women in Medicine and Health Sciences programme, including

Opportunities for creating networks, interacting and collaborating with one another

- Networking events (meeting leaders, founding women's events)

- Internal career development (mentorship clinics, leadership clinics)

- External career development (public speaking, salary negotiations)

- Work/life balance education (elder care workshops)

- Leadership and mentoring opportunities

Professional development workshops and lectures

School of Medicine implemented Provost's Advisory Committee on the Status of Women Faculty. Interventions included recruitment of diverse faculty, faculty awards, professional development programmes, intensive mentoring, skill building workshops, professional networking programme

$\begin{array}{llll}\begin{array}{l}\text { Helitzer et } a l^{41} \\ \text { USA }\end{array} & \begin{array}{l}\text { Multicomponent (ELAM and } \\ \text { others) }\end{array} & \begin{array}{l}\text { ELAM: } 1 \text { year } \\ \text { Others: } 3 \text { to } \\ 4 \text { days }\end{array} \\ & & & \\ \text { Levine et }\left.a\right|^{32} & \text { USA } & \text { Multicomponent } & 10 \text { months }\end{array}$

ELAM: see above

Early Career Women Faculty Professional Development Programme (EWIM): professional development seminars for women at instructor lecture or assistant professor level

Mid-Career Women Faculty Professional Development Programme (MidWIM): professional development seminars for women at associate professor or professor level

All women faculty invited to participate in the Leadership Programme for Women Faculty, including nine half-day workshop sessions including networking, role-play and reflective practice. Modules covered

- Collaboration skills

- Networking skills

Presentation skills

- Influence of gender on communication styles

- Agreement and conflict management

- Decision-making

- Facilitating group decision-making

- Leadership skills

$\begin{array}{llll}\text { Chang et } a l^{35} & \text { USA } & \begin{array}{l}\text { Multicomponent (ELAM and } \\ \text { others) }\end{array} & \begin{array}{l}\text { ELAM: } 1 \text { year } \\ \text { Others: } 3 \text { to } \\ 4 \text { days }\end{array} \\ \text { Girod et } a l^{44} & \text { USA } & \text { Peer education } & 20 \text { min }\end{array}$

ELAM: see above

EWIM: see above MidWIM: see above

Standardised presentation by Medicine department leaders summarising research literature on implicit bias, particularly in reference to gender and leadership Includes

- Data about the existence and effects of unconscious gender bias

Tips for overcoming bias in hiring processes

CV, curriculum vitae.

the end of the intervention only ${ }^{394} 4247$ and seven implemented pre-programme and post-programme measures. ${ }^{31} 323437404445$ Several methodological limitations were noted during critical appraisal (table 2), including that eight studies did not use validated tools to measure their outcomes and nine did not include adequate description of participants. None of the observational or post-test only studies identified or appropriately controlled for relevant confounds, and six (of 10) before-and-after and controlled studies did not provide enough detail about data loss at follow-up. Most studies did not include repeat follow-up to assess for sustained effects of the intervention. JBI Checklist scores ranged from $2 / 7(28.5 \%)$ to $6 / 9(66.7 \%)$.

\section{Interventions}

Three studies ${ }^{36-38}$ evaluated the efficacy of the Hedwig van Amerigen Executive Leadership in Academic Medicine for women programme (ELAM) with overlapping samples. ELAM is an American 1-year leadership training programme for senior academic women with coaching, networking and mentoring opportunities. Participants meet for a week at the beginning and end of the year, once in between this time, and submit assignments regularly. The curriculum aims to improve skills in paradigms of leadership, financial management, strategic planning, emerging issues in academic medicine, communication, personal dimensions of leadership and career advancement strategies. ${ }^{38}$ An additional two studies compared 


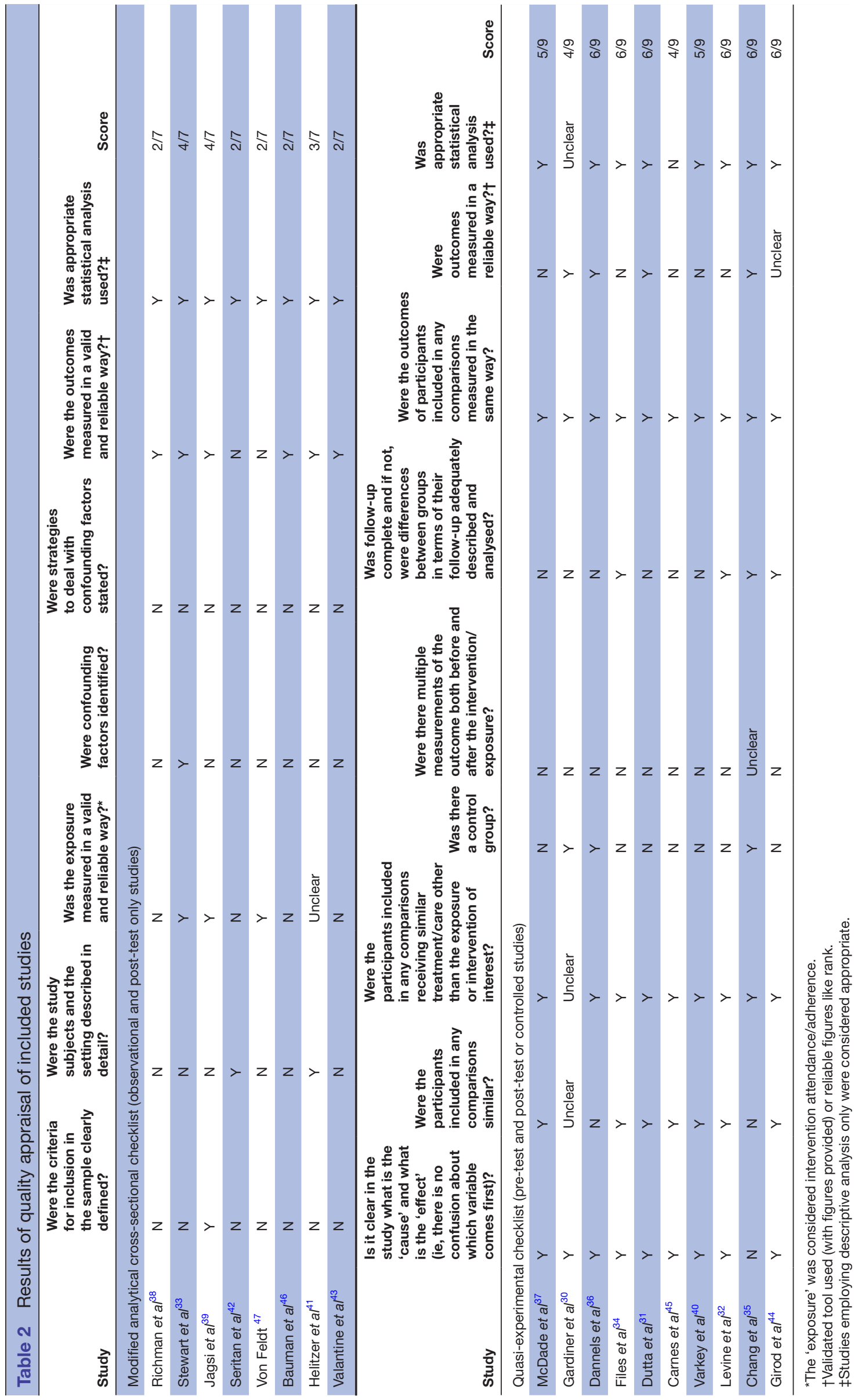

응 
outcomes from ELAM with less intensive multicomponent interventions involving professional development seminars only. ${ }^{35}$ Four studies evaluated other multicomponent interventions, which involved two or more of peer mentoring, education and skill building sessions, networking and improved access to resources (such as child care or grant funding). ${ }^{32424346}$ These interventions were delivered over 10 months, ${ }^{32} 1$ year ${ }^{46}$ or on an ongoing basis. ${ }^{43}$ One-year peer mentoring programmes were evaluated in four studies. ${ }^{30} 313440$ Three studies evaluated the impact of peer education sessions about implicit and explicit bias against women in academia, with strategies to address this bias and improve hiring practices. 33445 The final two studies evaluated the efficacy of provision of a US\$30000 grant to enable research and professional development for women responsible for the care of children $^{39}$ and a short curriculum vitae (CV) review and feedback session. ${ }^{47}$

\section{Efficacy of interventions}

The included studies reported on a range of outcomes that could be categorised into (1) self-reported skills and capabilities, (2) gender bias, (3) satisfaction with the programme and (4) tangible outcomes including faculty representation, retention, rank and remuneration. All of the included studies reported positive outcomes on at least one measure. A snapshot summary of outcomes appears in table 3 and detailed findings in table 4 .

\section{Self-reported leadership capability and skills}

Eight studies measured self-rated leadership capabilities and skills and all reported positive results following intervention. Four of these studies evaluated programmes that involved a number of components. One controlled beforeand-after study reported that those enrolled in the ELAM programme rated their leadership capability more highly after the programme than matched control participants

Table 3 Summary of outcomes

\begin{tabular}{|c|c|c|c|c|c|c|}
\hline \multirow[b]{2}{*}{ Study } & \multirow[b]{2}{*}{ Intervention } & \multicolumn{5}{|c|}{ Positive outcome reported by authors } \\
\hline & & $\begin{array}{l}\text { Self- } \\
\text { reported } \\
\text { skills }\end{array}$ & Bias & $\begin{array}{l}\text { Representation, } \\
\text { promotion, } \\
\text { retention, } \\
\text { remuneration }\end{array}$ & $\begin{array}{l}\text { Satisfaction } \\
\text { with } \\
\text { programme }\end{array}$ & $\begin{array}{l}\text { Satisfaction with } \\
\text { career, well- } \\
\text { being }\end{array}$ \\
\hline \multicolumn{7}{|l|}{ Multicomponent } \\
\hline Richman et $\left.a\right|^{38}$ & ELAM & & & Yes & & \\
\hline Seritan et al ${ }^{42}$ & Other multicomponent & & & $\begin{array}{l}\text { Yes (representation); } \\
\text { no (rank) }\end{array}$ & Yes & \\
\hline Dannels et $\left.a\right|^{36}$ & ELAM & Yes & & Yes & & \\
\hline Bauman et $\mathrm{al}^{46}$ & Other multicomponent & & & Yes & & Yes \\
\hline Valantine et al $^{43}$ & Other multicomponent & & & Yes & & Yes \\
\hline Chang et $a l^{35}$ & $\begin{array}{l}\text { ELAM and other } \\
\text { multicomponent }\end{array}$ & & & Yes & & \\
\hline \multicolumn{7}{|l|}{ Peer education } \\
\hline Stewart et $\left.a\right|^{33}$ & Peer education & & & Yes & & \\
\hline Carnes et $a^{45}$ & Peer education & & Yes & & & \\
\hline Girod et al ${ }^{44}$ & Peer education & & Yes & & & \\
\hline \multicolumn{7}{|l|}{ Peer mentoring } \\
\hline Gardiner et $a l^{30}$ & Peer mentoring & Yes & & Yes & & No \\
\hline Files et $a l^{34}$ & Peer mentoring & Yes & & Yes & & \\
\hline
\end{tabular}

CV, curriculum vitae; ELAM, Executive Leadership in Academic Medicine programme. 


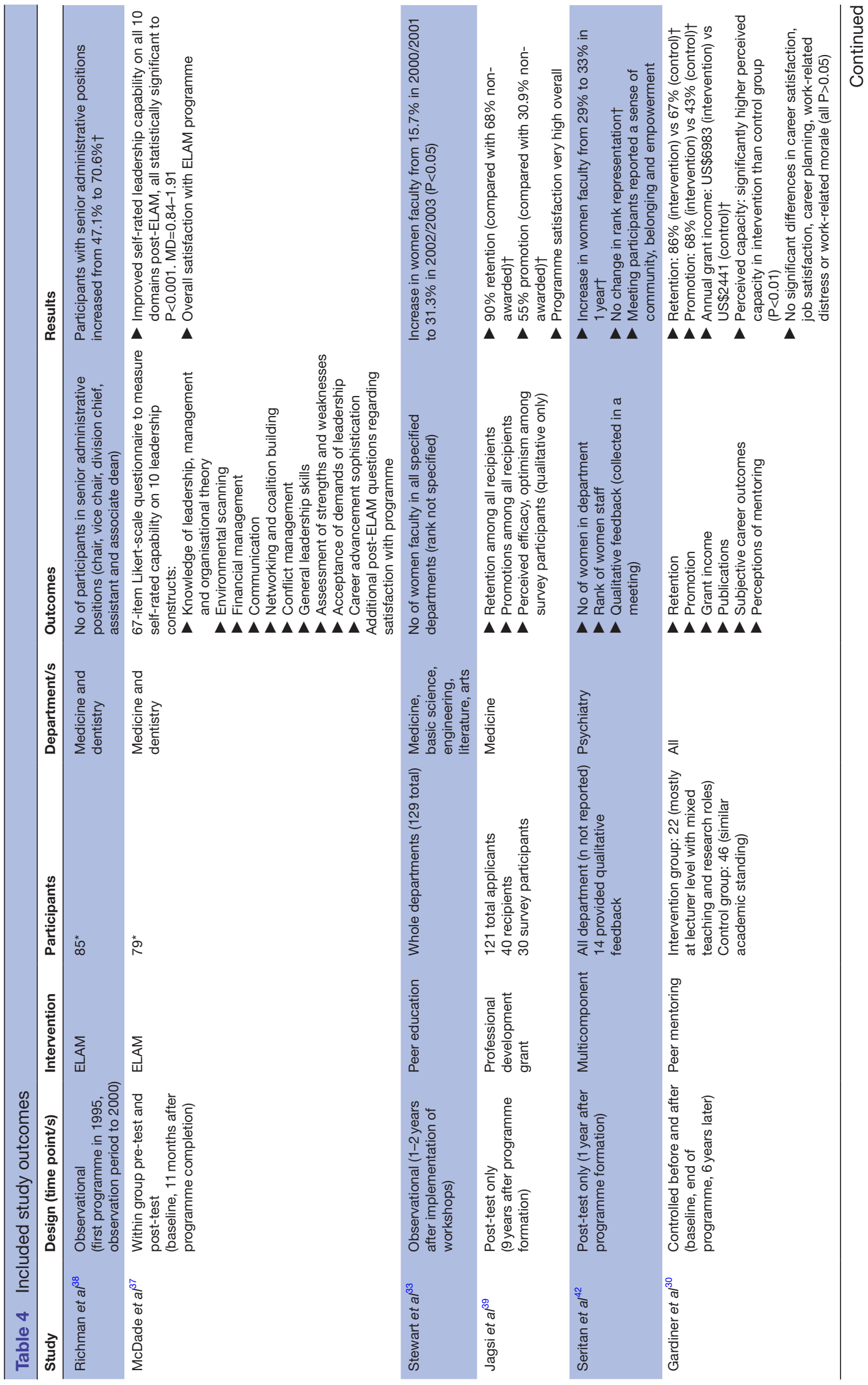




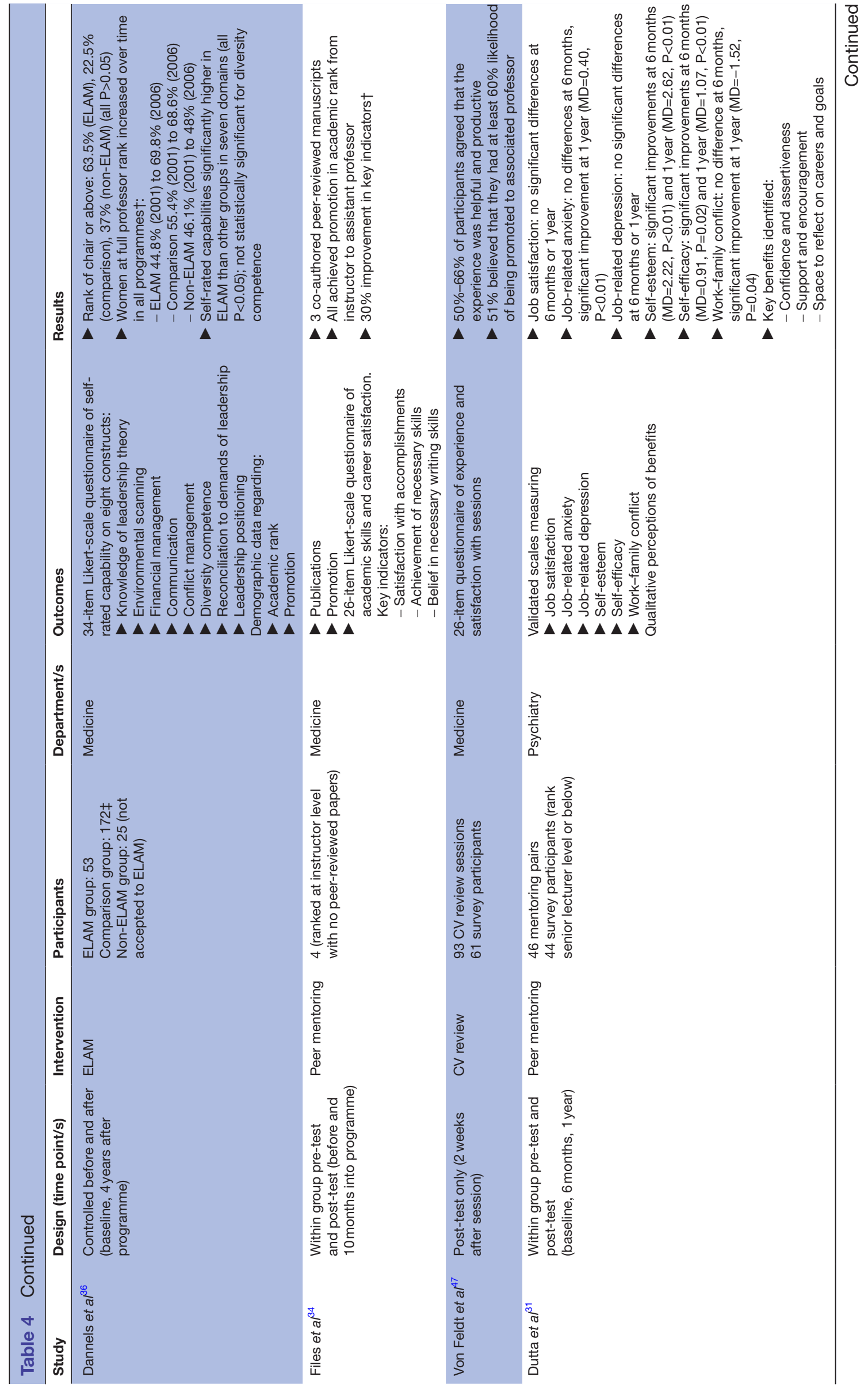




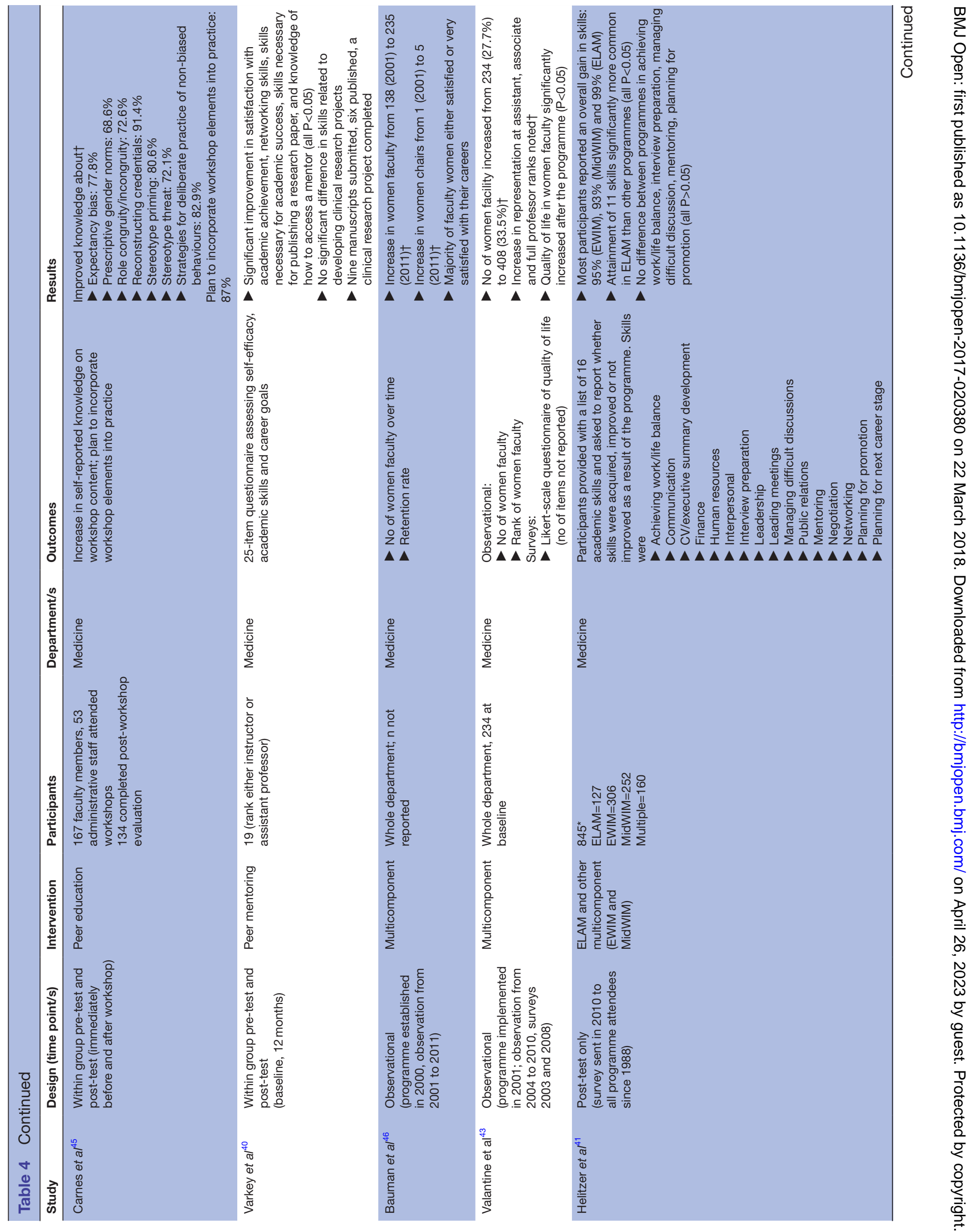




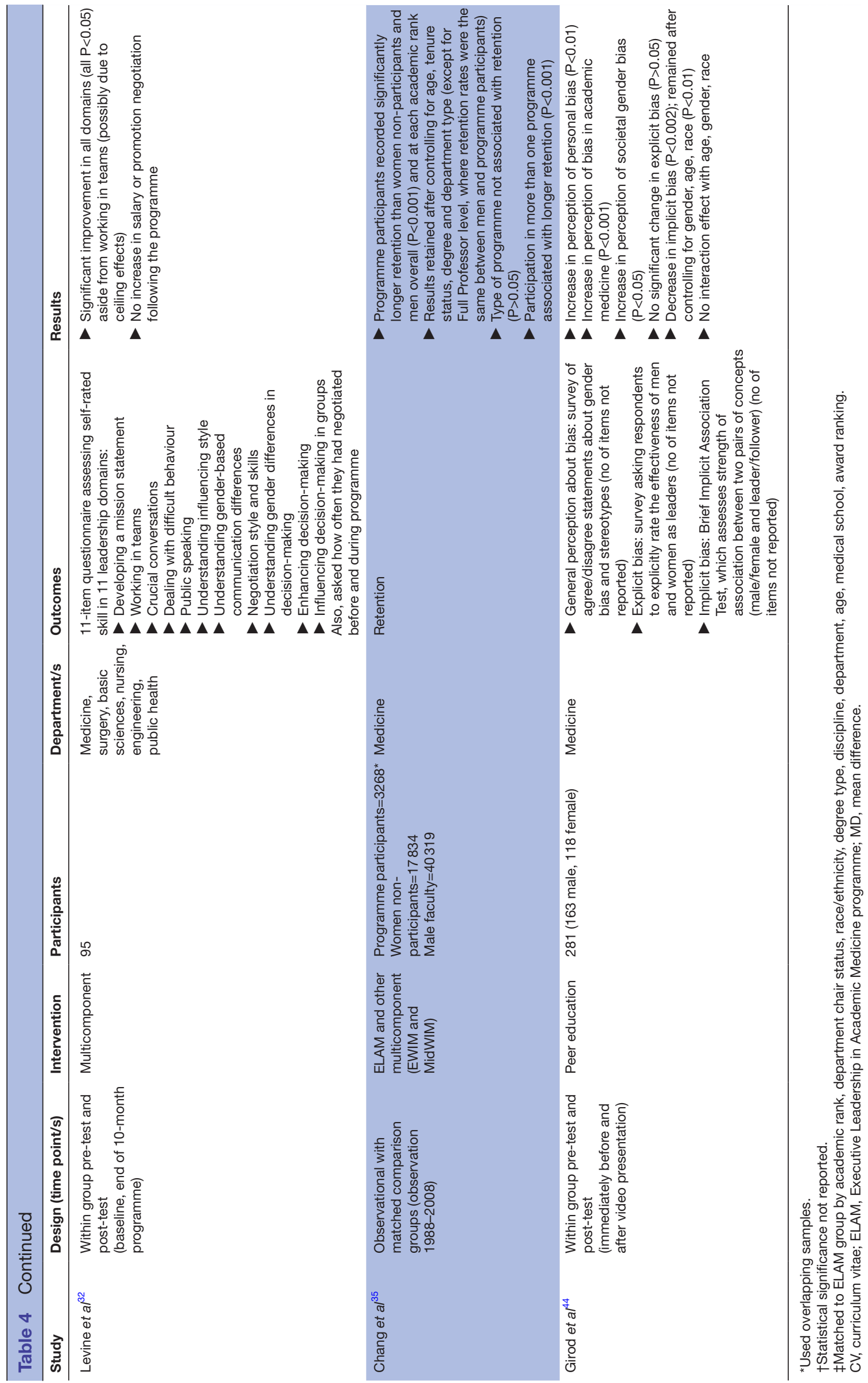


or those not accepted into the ELAM programme. However, the authors did not specify or control for reasons for non-admission to the programme. ${ }^{36}$ Similarly, McDade $e t a l^{37}$ reported significant improvements in all 10 domains of leadership capability following participation in the ELAM programme but did not include a comparison group. The benefits of multicomponent programmes were not unique to ELAM; Helitzer and colleagues $^{41}$ found that nearly all participants in any one of three multicomponent programmes (including ELAM) reported an overall gain in leadership skills, while Levine and colleagues ${ }^{32}$ found that participants in their multicomponent programme (including nine half-day workshops and networking) reported post-intervention improvements in most reported leadership domains including developing a mission statement, dealing with difficult behaviour and influencing decision-making.

Peer mentoring programmes were also universally linked to improved self-rated skills. Dutta $e t a l^{\beta 1}$ reported that self-rated well-being, self-esteem and self-efficacy all improved following a 1-year peer mentoring programme, while Varkey et $a t^{t 0}$ noted significant improvements in writing, networking, critical appraisal and other skills. However, none of these studies of peer mentoring included a comparison group. Of the eight studies reporting on self-rated skills, only two explored whether benefits extended to tangible outcomes, with conflicting results. ${ }^{32} 36$

\section{Gender bias}

Both Girod $e t a t^{44}$ and Carnes $e t a l^{45}$ noted a significant increase in knowledge of gender bias and awareness of one's own bias in academic medicine following a once-off peer education session. Carnes $e t a t^{45}$ additionally noted that $87 \%$ of workshop participants indicated an intention to change their practice as a result, but did not assess whether this occurred. Neither of these studies reported whether the education translated to improved conditions for women faculty.

\section{Satisfaction with programme}

Four studies reported that there were high levels of participant satisfaction with an intervention. This included development of a sense of community and empowerment $\mathrm{t}^{42}$ and increased career satisfaction ${ }^{46}$ following participation in a multicomponent intervention including peer mentoring, networking and professional development, and appreciation of peer feedback and practical skills in manuscript preparation. ${ }^{34}$ Von Feldt and colleagues ${ }^{47}$ reported that a brief CV review session was moderately successful with $50 \%-66 \%$ of participants reporting the session to be helpful and productive. None of these studies established whether these benefits extended to tangible outcomes.

\section{Representation, promotion, retention and remuneration}

Eleven studies reported the impact of interventions on career outcomes for women including faculty representation, promotion, retention and pay. Seven were evaluations of multicomponent programmes, and five of these reported positive outcomes. In addition to selfrated leadership capabilities, Dannels $e t a l^{36}$ noted a significant improvement in rank among participants of ELAM relative to other programmes. Similarly, Chang et $a \hat{l}^{35}$ compared 20-year retention rates between ELAM or other (less intensive) multicomponent programme participants, non-participating women faculty and matched male faculty. Programme participants at all levels recorded significantly longer retention at their institution than non-participating women and equivalent or longer retention when compared with men. These effects remained even after controlling for age, tenure status, degree and department type (clinical, basic science, other). Three other uncontrolled studies reported increased representation of women in senior positions concurrent with implementation of ELAM $^{38}$ or other multicomponent interventions, ${ }^{43}{ }^{46}$ but did not establish whether the increase was statistically significant or attributable to programme participation. Similarly, Seritan et $a t^{42}$ noted an overall $4 \%$ increase in women faculty 1 year after implementing their multicomponent programme including peer mentoring, online collaborations and professional development, but did not report the statistical significance of this. However, there was no change in rank representation among participating women. This is consistent with Kazemi and colleagues, ${ }^{48}$ who reported that despite increased self-reported capability (see above) there were no significant increases in salary or promotion following their multicomponent programme (though they did not include a comparison group).

Both studies reporting on tangible outcomes following mentoring programmes reported positive results but were of low methodological quality. One reported that all four participants were promoted within 1 year (but did not compare this to non-participating faculty),${ }^{34}$ while the other reported higher rates of retention, promotion and grant income compared with non-participating women (but did not report the statistical significance of this).$^{30}$

Jagsi and colleagues ${ }^{39}$ reported that $55 \%$ of women responsible for the care of children who had received an internal financial grant were promoted within a year, compared with $31 \%$ who had not received the grant. Grant recipients reported feeling more optimistic about their careers and that the grant helped them to overcome impediments related to taking time off to care for children. Authors also noted that subsequent funding received by grant participants far exceeded institutional cost of the programme.

Finally, Stewart et $a \hat{l}^{3}$ reported that female faculty doubled in the 2years following establishment of a committee of full professors in science and engineering who received extensive education and delivered workshops to other staff about gender bias in academia and strategies to improve recruitment of female staff. However, the authors note several factors that could account for this change aside from the intervention (but were not controlled for in analysis), including that 
the departments included in the analysis were all led by members of the committee. In addition, an institutional report was released during the follow-up period criticising the academic climate of the University and a departmental grant was subsequently made available for individual departments to address inequalities.

\section{DISCUSSION}

To our knowledge, this is the first review to identify and synthesise quantitative results of programmes that had operated in academic institutions to improve career outcomes for women. Eighteen eligible studies were identified, evaluating a range of structured programmes typically including peer mentoring, education and skill development, and networking opportunities. Study quality was low to moderate overall. All studies reported positive outcomes on at least one indicator. Most often these were related to self-rated skills and capability, or satisfaction with the interventions. Eleven of the studies included in the review reported how these benefits translated to concrete outcomes like promotion, retention, grant success and pay, with mixed results. ${ }^{30} 32-34363839424346$

\section{Main findings}

The ELAM programme was evaluated in five studies, though four of these were conducted at the same University and used overlapping samples. ${ }^{35} 373841$ The benefits of ELAM outside its original institution and transferability to other disciplines cannot be established from existing literature. Nonetheless, the programme had a positive effect on the rank, retention and/or self-rated capabilities of women faculty in all studies. Benefits of ELAM may be greater than those achieved by other multicomponent programmes, with one study demonstrating a greater increase in self-rated skills after ELAM than from two other programmes comprising professional development seminars only. ${ }^{41}$ Authors attribute these added benefits to the greater length and intensity of ELAM, and intentional community building with other female staff. A more recent study using the same database of participants, however, did not find any difference in retention between the same programmes. ${ }^{35}$ This may reflect that the benefits of more intensive programmes do not extend to tangible outcomes.

Mentoring was a central component of almost all multicomponent programmes and was evaluated separately in four studies. Although the nature and content of mentoring varied, positive effects were noted in all studies including improvement in perceived skills and self-esteem, ${ }^{31}{ }^{40}$ and in one study higher retention and promotion rates. ${ }^{30}$ The mutual benefits available to universities by investing in junior women academics were exemplified by one study that evaluated a professional development grant programme for women responsible for the care of children. Authors remarked at the significant return on investment generated by the scheme, as recipients had achieved an income of more than US $\$ 51$ million in grants and investments after the faculty invested just over US $\$ 2$ million. ${ }^{39}$ This is congruent with evidence to suggest that diversity among staff contributes positively to an organisation's financial health. ${ }^{25}$ Recipients of the grant noted that its existence had a positive impact on the institutional culture, as it promoted optimism about the potential to balance an academic career with child rearing.

The importance of tailoring an intervention to the life and career stage of the woman was well acknowledged during intervention design in all studies. Programmes intended for junior faculty typically addressed known barriers to career progression including lack of role models and mentors, fewer networks and difficulty managing family and work responsibilities. ${ }^{8}$ On the other hand, programmes for more senior women focused on developing skills in administrative leadership and overcoming the systemic barriers that prevent women from reaching leadership positions. ${ }^{38}$ Very few of the studies discussed the impact of rank on the experience and outcomes of programme participation, and this is a valuable avenue for future research.

Despite the positive outcomes reported in most studies, more work is required to inform design of high-quality and efficacious programmes to support the careers of women in academia. Few studies evaluated their intervention of interest in depth, establishing the most efficacious components, environmental factors that impacted outcomes or sustainability of benefits. Most were designed without a suitable control or other comparison group, and it is not possible to know whether results are attributable to the intervention or other factors. Effects noted in observational studies in particular could reflect other political, economic, cohort or organisational change. Most studies enrolled relatively small samples, with limited power to detect meaningful differences. Additionally, few of the included studies addressed the impact of self-selection and the pre-existing differences between those who participated in the intervention and those who did not. While participation in a given programme is known to vary according to personal preferences, formal and informal support, perceived efficacy and other barriers, ${ }^{49}$ few studies reported on these factors. Importantly, the included studies did not discuss the factors that impeded programme participation in the first place and results may therefore reflect only those willing and able to take part. These factors may also affect participant success. Overall, comprehensive process evaluations are notably missing from the evidence base and will be beneficial to establish programme efficacy, acceptability, sustainability and transferability in the future.

All of the interventions were implemented in academic medicine departments, which historically contain more men than women ${ }^{44}$ and in which academics often split their time with clinical positions. Many of the programmes trialled here (including ELAM) were specifically designed for academic medicine and may not be similarly efficacious in other areas. None of the three 
studies that included more than one faculty compared outcomes between them. In addition, all but two studies were conducted in the USA where academic staff are less likely (than UK academics, for example) to be unionised, are more often subject to a University-specific pay scale and are able to receive tenure. ${ }^{50}$ These structural differences may also affect success. Low-income and middle-income countries were not represented at all. The importance of intersecting oppressions (ie, gender, race, disability and so on) was also not addressed in any study, though this may reflect our review design and exclusion of studies programmes addressing multiple disadvantages (eg, for women of colour). These factors are likely to be crucial predictors of success and should be addressed during intervention design or by statistical controlling in future studies.

It was noted that the interventions trialled in the included studies generally implemented a 'bottom-up' approach in which women were responsible for opting in and participating. Such interventions may be unsuccessful where the woman feels her efforts would be futile or met with hostility. Few programmes with a 'top-down' approach, in which senior management are tasked with improving conditions for their disadvantaged colleagues, were identified in this review. This approach was successful when used: Stewart $e t a l^{33}$ attribute the doubling of female staff over 2 years in their study to an institution-wide change in culture starting with senior management and full professors. The Athena Scientific Women's Academic Network (SWAN) Charter is a widely used example of a 'top-down' intervention, involving evaluation and accreditation standards to recognise organisations that perform well in terms of employment practices that support equality. ${ }^{51}$ Qualitative reports about Athena SWAN have noted a high level of satisfaction with the programme and that participating organisations had changed their procedures to reflect the key principles of the charter. ${ }^{5253}$ Whether this work is translating to short-term or long-term improvements in senior academic representation is yet to be reported and should be explored in future research. Some qualitative evaluations of Athena SWAN have noted concerns that women are still burdened with much of the responsibility to implement it. ${ }^{26}$ Extant institutional financial support programmes and re-entry fellowships that support women returning from care leave are also good candidates for trial.

\section{Limitations of review}

Interpretation of the results of this review should take into consideration that a lack of comparable studies meant that a quantitative meta-analysis was not possible in this case. Publication bias in favour of significant findings is possible, and the lack of homogeneity in methods and outcomes of studies included in this review left us unable to formally test for this. That all included studies reported a positive outcome on at least one indicator (or did not report statistical significance) increases the risk of bias.

\section{CONCLUSION}

This review builds on research to date that has predominantly examined the extent of and potential contributors to gender inequality in academia. It provides some insight into the potential for low-cost interventions to address these factors and provide mutually beneficial outcomes for women staff and institutions as a whole. However, the studies identified provide limited highquality evidence to guide programme design. Rigorous assessment of programme efficacy and sustainability is required across countries and academic departments, with appropriate comparison groups and controlling for relevant confounders. Given the importance of reducing gender bias in academia, it is perhaps best to conclude here that something is better than nothing. The success of an intervention is undermined where it relies on the additional labour of those it is intending to support. Innovative programmes that provide incentives for those with the most power to remove barriers to women in academia will likely be required to create sustainable change.

Contributors KEL and IJP conceptualised and designed the review. KEL and $M C$ reviewed titles, abstracts and full-text papers for eligibility. Authors resolved disagreement by discussion or, where necessary, IJP offered their view. 10 was responsible for extracting data and all data extraction was verified by MC. KEL and $M C$ independently assessed the methodological quality of each study. KEL and MC prepared the manuscript. KEL, IJP, MC, IO, KG and JDC reviewed and edited the manuscript.

Funding This research received no specific grant from any funding agency in the public, commercial or not-for-profit sectors.

Competing interests None declared.

Patient consent Not required.

Provenance and peer review Not commissioned; externally peer reviewed.

Data sharing statement No original data were generated for this study.

Open Access This is an Open Access article distributed in accordance with the Creative Commons Attribution Non Commercial (CC BY-NC 4.0) license, which permits others to distribute, remix, adapt, build upon this work non-commercially, and license their derivative works on different terms, provided the original work is properly cited and the use is non-commercial. See: http://creativecommons.org/ licenses/by-nc/4.0/

(c) Article author(s) (or their employer(s) unless otherwise stated in the text of the article) 2018. All rights reserved. No commercial use is permitted unless otherwise expressly granted.

\section{REFERENCES}

1. Australian Human Rights Commission. About sex discrimination. 2016 https://www.humanrights.gov.au/our-work/sex-discrimination/ about-sex-discrimination

2. Government Equalities Office. Think, act, report framework, 2015.

3. Department of Education. Selected higher education statistics - 2015 staff data. Australia, 2015.

4. Jena $A B$, Khullar D, Ho O, et al. Sex differences in academic rank in US medical schools in 2014. JAMA 2015;314:1149-58.

5. Blandford E, Brill C, Neave S, et al. Equality in higher education: statistical report 2011. London: Equality Challenge Unit, 2011.

6. Fitzpatrick S. A survey of staffing levels of medical clinical academics in UK medical schools as at 31 July 2011. London: Medical Schools Council, 2012.

7. Pritchard R. Gender inequality in British and German universities. Compare 2007;37:651-69.

8. Howe-Walsh L, Turnbull S. Barriers to women leaders in academia: tales from science and technology. Stud High Educ 2016;41:415-28. 
9. Lautenberger DM, Dandar VM, Raezer CL, et al. The state of women in academic medicine: the pipeline and pathways to leadership. Washington DC: Association of American Medical Colleges, 2014.

10. Nielsen MW. Scandinavian approaches to gender equality in academia: a comparative study. Scand J Educ Res 2017;61:295-318.

11. y Muhs GG, Niemann YF, González CG, et al. Presumed incompetent: the intersections of race and class for women in academia: University Press of Colorado, 2012.

12. Mayer AP, Files JA, Ko MG, et al. Academic advancement of women in medicine: do socialized gender differences have a role in mentoring? Mayo Clin Proc 2008;83:204-7.

13. Holliday EB, Jagsi R, Wilson LD, et al. Gender differences in publication productivity, academic position, career duration, and funding among U.S. academic radiation oncology faculty. Acad Med 2014:89:767-73.

14. Head MG, Fitchett JR, Cooke MK, et al. Differences in research funding for women scientists: a systematic comparison of UK investments in global infectious disease research during 1997-2010. BMJ Open 2013;3:e003362.

15. Filardo G, da Graca B, Sass DM, et al. Trends and comparison of female first authorship in high impact medical journals: observational study (1994-2014). BMJ 2016;352:i847.

16. Carr PL, Gunn CM, Kaplan SA, et al. Inadequate progress for women in academic medicine: findings from the National Faculty Study. $J$ Womens Health 2015;24:190-9.

17. van den Brink M, Benschop Y. Gender practices in the construction of academic excellence: sheep with five legs. Organization 2012;19:507-24.

18. Moss-Racusin CA, Dovidio JF, Brescoll VL, et al. Science faculty's subtle gender biases favor male students. Proc Natl Acad Sci U S A 2012;109:16474-9.

19. Bismark M, Morris J, Thomas L, et al. Reasons and remedies for under-representation of women in medical leadership roles: a qualitative study from Australia. BMJ Open 2015;5:e009384.

20. Rudman LA. Self-promotion as a risk factor for women: the costs and benefits of counterstereotypical impression management. $J$ Pers Soc Psychol 1998;74:629-45.

21. Budig MJ, Hodges MJ. Differences in disadvantage variation in the motherhood penalty across white women's earnings distribution. Am Sociol Rev 2010;75:705-28.

22. Böckmann I, Misra J, Budig M. Mothers' employment in wealthy countries: how do cultural and institutional factors shape the motherhood employment and working hours gap? citeseer, 2013.

23. Klocker N, Drozdzewski D. Commentary: career progress relative to opportunity: how many papers is a baby 'worth'? 2012.

24. Monroe K, Ozyurt S, Wrigley T, et al. Gender equality in academia: bad news from the trenches, and some possible solutions. Perspectives on Politics 2008;6:215-33.

25. Catalyst. The bottom line: connecting corporate performance and gender diversity: Catalyst, 2004

26. Caffrey L, Wyatt $D$, Fudge $\mathrm{N}$, et al. Gender equity programmes in academic medicine: a realist evaluation approach to Athena SWAN processes. BMJ Open 2016;6:e012090.

27. Ovseiko PV, Edmunds LD, Pololi LH, et al. Markers of achievement for assessing and monitoring gender equity in translational research organisations: a rationale and study protocol. BMJ Open 2016;6:e009022.

28. Institute TJB. Joanna Briggs Institute reviewers' manual. Edition ed. Australia: The Joanna Briggs Institute, 2016.

29. Sanderson S, Tatt ID, Higgins JP. Tools for assessing quality and susceptibility to bias in observational studies in epidemiology: a systematic review and annotated bibliography. Int J Epidemiol 2007;36:666-76.

30. Gardiner M, Tiggemann M, Kearns H, et al. Show me the money! An empirical analysis of mentoring outcomes for women in academia. High Edu Res Dev 2007;26:425-42.

31. Dutta R, Hawkes SL, Kuipers E, et al. One year outcomes of a mentoring scheme for female academics: a pilot study at the Institute of Psychiatry, King's College London. BMC Med Educ 2011;11:13.
32. Levine RB, González-Fernández M, Bodurtha J, et al. Implementation and evaluation of the Johns Hopkins University School of Medicine leadership program for women faculty. J Womens Health 2015;24:360-6.

33. Stewart AJ, La Vaque-Manty D, Malley JE. Recruiting female faculty members in science and engineering: preliminary evaluation of one intervention model. J Women Minor Sci Eng 2004;10:361-75.

34. Files JA, Blair JE, Mayer AP, et al. Facilitated peer mentorship: a pilot program for academic advancement of female medical faculty. $J$ Womens Health 2008;17:1009-15.

35. Chang S, Morahan PS, Magrane D, et al. Retaining faculty in academic medicine: the impact of career development programs for women. J Womens Health 2016;25:687-96.

36. Dannels SA, Yamagata H, McDade SA, et al. Evaluating a leadership program: a comparative, longitudinal study to assess the impact of the Executive Leadership in Academic Medicine (ELAM) Program for Women. Acad Med 2008;83:488-95.

37. McDade SA, Richman RC, Jackson GB, et al. Effects of participation in the Executive Leadership in Academic Medicine (ELAM) program on women faculty's perceived leadership capabilities. Acad Med 2004;79:302-9.

38. Richman RC, Morahan PS, Cohen DW, et al. Advancing women and closing the leadership gap: the Executive Leadership in Academic Medicine (ELAM) program experience. J Womens Health Gend Based Med 2001;10:271-7.

39. Jagsi R, Butterton JR, Starr R, et al. A targeted intervention for the career development of women in academic medicine. Arch Intern Med 2007;167:343-5.

40. Varkey P, Jatoi A, Williams A, et al. The positive impact of a facilitated peer mentoring program on academic skills of women faculty. $B M C$ Med Educ 2012;12:14.

41. Helitzer DL, Newbill SL, Morahan PS, et al. Perceptions of skill development of participants in three national career development programs for women faculty in academic medicine. Acad Med 2014;89:896-903.

42. Seritan AL, Bhangoo R, Garma S, et al. Society for women in academic psychiatry: a peer mentoring approach. Acad Psychiatry 2007;31:363-6

43. Valantine HA, Grewal D, Ku MC, et al. The gender gap in academic medicine: comparing results from a multifaceted intervention for stanford faculty to peer and national cohorts. Acad Med 2014:89:904-11.

44. Girod S, Fassiotto M, Grewal D, et al. Reducing implicit gender leadership bias in academic medicine with an educational intervention. Acad Med 2016;91:1143-50.

45. Carnes M, Devine PG, Isaac $C$, et al. Promoting institutional change through bias literacy. J Divers High Educ 2012;5:63-77.

46. Bauman MD, Howell LP, Villablanca AC. The women in medicine and health science program: an innovative initiative to support female faculty at the University of California Davis School of Medicine. Acad Med 2014;89:1462-6.

47. Von Feldt JM, Bristol M, Sonnad S, et al. The brief CV review session: one component of a mosaic of mentorship for women in academic medicine. J Natl Med Assoc 2009;101:873-80.

48. Kazemi DM, Levine MJ, Dmochowski J, et al. Effects of motivational interviewing intervention on blackouts among college freshmen. $J$ Nurs Scholarsh 2013;45:221-9.

49. Andersen RM. Revisiting the behavioral model and access to medical care: does it matter? J Health Soc Behav 1995;36:1-10.

50. Bennion A, Locke W. The early career paths and employment conditions of the academic profession in 17 countries. European Review 2010;18(S1):S7-33.

51. Donald A, Harvey PH, McLean AR. Athena SWAN awards: bridging the gender gap in UK science. Nature 2011:478:36.

52. Unit EC, Swan A. Evaluating the effectiveness and impact of the Athena SWAN charter: executive summary. UK, 2014.

53. Ovseiko PV, Chapple A, Edmunds LD, et al. Advancing gender equality through the Athena SWAN Charter for Women in Science: an exploratory study of women's and men's perceptions. Health Res Policy Syst 2017;15:12. 